\title{
Modeled Arctic sea ice evolution through 2300 in CMIP5 extended RCPs
}

\author{
P. J. Hezel ${ }^{1, *}$, T. Fichefet ${ }^{1}$, and F. Massonnet ${ }^{1}$ \\ ${ }^{1}$ Georges Lemaître Centre for Earth and Climate Research (TECLIM), Earth and Life Institute, \\ Université catholique de Louvain, Louvain-la-Neuve, Belgium \\ *now at: Geophysical Institute, University of Bergen, and Bjerknes Centre for Climate Research, Bergen, Norway
}

Correspondence to: P. J. Hezel (paul.hezel@uib.no)

Received: 20 December 2013 - Published in The Cryosphere Discuss.: 25 February 2014

Revised: 25 May 2014 - Accepted: 2 June 2014 - Published: 11 July 2014

\begin{abstract}
Almost all global climate models and Earth system models that participated in the Coupled Model Intercomparison Project 5 (CMIP5) show strong declines in Arctic sea ice extent and volume under the highest forcing scenario of the representative concentration pathways (RCPs) through 2100, including a transition from perennial to seasonal ice cover. Extended RCP simulations through 2300 were completed for a subset of models, and here we examine the time evolution of Arctic sea ice in these simulations. In RCP2.6, the summer Arctic sea ice extent increases compared to its minimum following the peak radiative forcing in 2044 in all nine models. RCP4.5 demonstrates continued summer Arctic sea ice decline after the forcing stabilizes due to continued warming on longer timescales. Based on the analysis of these two scenarios, we suggest that Arctic summer sea ice extent could begin to recover if and when radiative forcing from greenhouse gas concentrations were to decrease. In RCP8.5 the Arctic Ocean reaches annually ice-free conditions in seven of nine models. The ensemble of simulations completed under the extended RCPs provide insight into the global temperature increase at which sea ice disappears in the Arctic and the reversibility of declines in seasonal sea ice extent.
\end{abstract}

\section{Introduction}

The modeled decline in summer Arctic sea ice through 2100 is well documented (e.g., Stroeve et al., 2012; Massonnet et al., 2012) for the representative concentration pathways (RCPs) in the Coupled Model Intercomparison Project 5 (CMIP5) (Taylor et al., 2012). A subset of the CMIP5 model simulations were continued through 2300 following the extended concentration pathways, hereafter "extended RCPs", for RCP2.6, RCP4.5, and RCP8.5 (Moss et al., 2010; Meinshausen et al., 2011). The extended RCPs follow trajectories after 2100 of continued decreasing forcing (RCP2.6), continued constant forcing (RCP4.5), and increasing then constant forcing (RCP8.5) (Fig. 1a). We document the first multimodel evaluation of the Arctic sea ice extent (SIE) from these extended RCPs in this paper, though SIE behavior has been documented elsewhere in some individual models ( $\mathrm{Li}$ et al., 2013; Meehl et al., 2012, 2013; Jahn and Holland, 2013). These simulations provide insight into two features of particular interest: the disappearance of Arctic sea ice, including winter sea ice in extended RCP8.5, and the reversibility of sea ice loss in the Arctic climate system.

The Arctic sea ice in coupled climate models responds prominently to changes in forcing. The global mean surface temperature is proportional to the forcing as long as the forcing continues to increase (e.g., Long and Collins, 2013) and is indicative of both the forcing and the global feedbacks. As the rate of increase in forcing slows and the forcing becomes constant in RCP4.5 and RCP8.5, both the global mean surface air temperature and Arctic surface air temperature continue to slowly increase as a result of the adjustment of climate system to the continued energy imbalance at the top of the atmosphere (Hansen et al., 2005; Held et al., 2010). To demonstrate the relationship between forcing and global mean temperature, the forcing and the global surface temperature response are shown in Fig. 1 for the three RCPs examined here: RCP2.6, RCP4.5 and RCP8.5. Extended RCP6.0 had only two models with sea ice concentration data through 

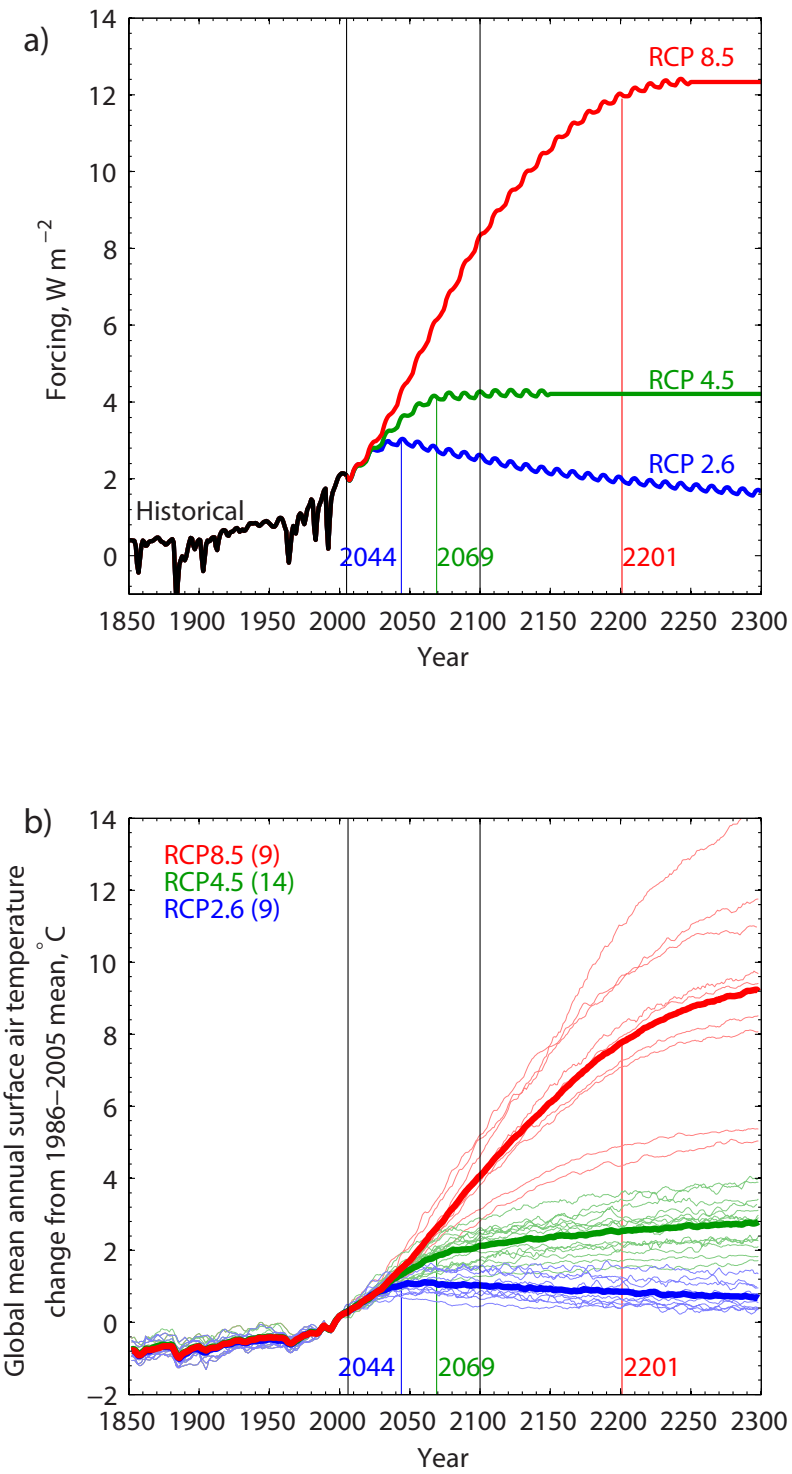

Figure 1. (a) Time series of forcing $\left(\mathrm{W} \mathrm{m}^{-2}\right)$ under each of the extended RCP scenarios for RCP2.6, RCP4.5, and RCP8.5. Historical forcing (black) covers the period 1850-2005, and the RCPs and extended RCPs are continued from 2006 and 2100. The year in which the forcing reaches its 11-year maximum (RCP2.6) or $97 \%$ of its maximum is shown by vertical lines (RCP4.5, RCP8.5). Data from Meinshausen et al. (2011). (b) Time series of annual global mean surface air temperature for RCP2.6 (blue), RCP4.5 (green), and RCP8.5 (red). Multi-model means are shown as dark solid lines, and lighter lines indicate individual ensemble members (5-year running mean). The number of models for each RCP is given in parentheses.

2300 and was not included in this analysis. For each RCP, the idealized net forcing shown here is calculated from the greenhouse gases and other forcing agents, including aerosol direct and indirect effects, as described in Meinshausen et al. (2011).
In this paper we discuss the changes in sea ice extent and volume with respect to the changes in global mean surface air temperature as a reflection of the forcing, although a discussion with respect to forcing itself or greenhouse gas concentrations is equally applicable (e.g., Jahn and Holland, 2013). Changes in sea ice can also be discussed with respect to Arctic regional surface air temperatures (e.g., Zhang, 2010), but it is difficult to separate the effect of warmer surface air temperatures driven by other causes (e.g., warm air advection, radiative changes due to clouds) that drive sea ice changes from the response of surface air temperature to reduced sea ice concentration, thinner sea ice, and thus increased oceanic heat flux to the atmosphere.

The disappearance of summer Arctic sea ice has important climatic, ecological and policy implications (e.g., AMAP, 2011), and there has been significant interest in projecting when the Arctic will reach a seasonally ice-free state. The CMIP5 archive itself does not satisfactorily constrain the dates of possible sea ice disappearance (Stroeve et al., 2012), and so several studies have selected a subset of models to narrow the prediction for the range of dates by which the Arctic will be ice-free (Massonnet et al., 2012; Wang and Overland, 2012; Liu et al., 2013). That approach assumes that the anthropogenic climate forcing follows a trajectory similar to that of a specific RCP. Sea ice disappearance or ice-free conditions are defined here as when sea ice extent first falls below $1 \times 10^{6} \mathrm{~km}^{2}$ for at least 5 consecutive years.

Following a slightly different approach, Mahlstein and Knutti (2012) estimated the global temperature increase at which models become ice-free based on the sensitivity of sea ice decline per degree temperature increase. This metric has been used in other studies (Zhang, 2010; Winton, 2011) to constrain models compared to observations or eliminate uncertainties in sea ice projections associated with errors in forcing or climate sensitivity. Mahlstein and Knutti (2012) used recalibrated sea ice extents from the CMIP3 model archive to overcome two related biases that cause a slower decline in modeled sea ice than in observations: the loss of sea ice per degree warming and the amount of polar amplification. In Sect. 4 of this paper we show that the CMIP5 models predict a global temperature increase at which the summer sea ice disappears consistent with Mahlstein and Knutti (2012), regardless of the model biases in sea ice extent, volume, and trends, and regardless of the forcing scenario. Furthermore, the extended RCP8.5 scenario reveals temperatures at which ice-free conditions persist in months beyond the September sea ice minimum.

The possibility of "tipping points" or abrupt changes in the Arctic climate system and specifically in relation to sea ice continues to be the subject of much discussion, though the meaning of the phrase "tipping point" varies (e.g., Lindsay and Zhang, 2005; Livina and Lenton, 2013; Lenton et al., 2008; Wadhams, 2012). In spite of the disagreement in terminology, the scientific questions focus on the reversibility of declining sea ice and the stability of different climate states 
Table 1. Models and number of available ensemble members for each of the extended RCPs. Only one ensemble member (r1i1p1) was used from each of the models in the analysis here.

\begin{tabular}{|c|c|c|c|}
\hline Model & $\mathrm{RCP} 2.6$ & $\mathrm{RCP} 4.5$ & RCP8.5 \\
\hline bcc-csm1.1 & 1 & 1 & 1 \\
\hline CanESM2 ${ }^{b}$ & 1 & 2 & - \\
\hline $\mathrm{CCSM} 4^{\mathrm{b}}$ & 1 & 1 & 1 \\
\hline CESM1-CAM5 ${ }^{\mathrm{b}}$ & 1 & 1 & - \\
\hline $\mathrm{CNRM}^{-\mathrm{CM}} 5^{\mathrm{b}}$ & - & 1 & 1 \\
\hline CSIRO-Mk3.6.0 & - & 3 & 3 \\
\hline GFDL-CM $3^{\mathrm{a}, \mathrm{b}}$ & - & 1 & - \\
\hline GISS-E2-H ${ }^{b}$ & 1 & 5 & 1 \\
\hline GISS-E2-R ${ }^{b}$ & 1 & 5 & 1 \\
\hline HadGEM2-ES ${ }^{b}$ & 1 & 1 & 1 \\
\hline IPSL-CM5A-LR & 1 & 1 & 1 \\
\hline IPSL-CM5A-MR ${ }^{\mathrm{a}, \mathrm{b}}$ & - & 1 & - \\
\hline MIROC-ESM & - & 1 & - \\
\hline MPI-ESM-LR & 1 & 1 & 1 \\
\hline
\end{tabular}

${ }^{a}$ Model meets all four criteria for matching observations in Massonnet et al. (2012). ${ }^{\mathrm{b}}$ Model meets criterion for sea ice extent trend within $20 \%$ of observed for September 1979-2012.

for the Arctic. Model studies have consistently shown that the Arctic sea ice recovers in experiments after the model is forced into an ice-free state. This is true for both annually ice-free conditions achieved via radiative forcing (Armour et al., 2011; Ridley et al., 2012) and for seasonally ice-free conditions achieved by imposed removal (Tietsche et al., 2011). Such results have been obtained in studies using a single model, and the CMIP5 archive under RCP2.6 affords a demonstration of reversibility of seasonal sea ice decline across multiple models, albeit for a relatively small change in forcing. In experiments using a change of forcing similar to RCP2.6 under the ENSEMBLES project (Johns et al., 2011), the sea ice did not show recovery on timescales up through 2100 (Körper et al., 2013). In Sect. 5, we examine the reversibility shown under RCP2.6 and demonstrate that the extended simulation through 2300 is required to distinguish the forced response from the variability. We summarize the conclusions in Sect. 6 and comment on the relevance of these results to policy decisions.

\section{Data and methods}

We analyzed sea ice fields (sea ice concentration and sea ice thickness) from the 14 CMIP5 models listed in Table 1 that had extended RCPs through 2300. Though four models have multiple ensemble members, we used only the first ensemble member from each model. Since our focus here is on the longer timescale response of the sea ice to changes in forcing, we are not as interested in the interannual variability from the few models with additional ensemble members, and the results do not change with their inclusion. Using monthly mean sea ice concentration, a monthly mean time series of sea ice extent was calculated for the Northern Hemisphere on the original model grids, with sea ice extent calculated as the total ocean-covered area of the grid cells where monthly mean sea ice concentration was in excess of $15 \%$. Though sea ice area may be a more physical metric (Notz, 2014), we have chosen to use sea ice extent rather than sea ice area for its ease of comparison to observations and previous studies. Sea ice volume was calculated using the sea ice thickness field, which is average ice thickness over the entire ocean-covered area of the grid cell. Sea ice volume therefore was computed as the product of the sea ice thickness and the ocean-covered area of the grid cells. Multi-model means of both time series were computed with a uniform weight for each model.

We apply the method of Massonnet et al. (2012) to compare modeled Arctic sea ice characteristics to observations using all available CMIP5 models. We note in Table 1 the models which match the observed trend in sea ice extent for 1979-2012 within $\pm 20 \%$ as well as which models are ultimately selected as most closely matching observations of September sea ice extent, annual cycle in sea ice extent, September sea ice volume from reanalysis, and September sea ice trend (Collins et al., 2013, Sect. 12.4.6.1). The conclusions drawn in this paper do not differ if we include all models listed or only those selected using the method of Massonnet et al. (2012).

To find the year in which the Arctic becomes sea ice-free for a given month, we find the first year in which the 5-year running mean of sea ice extent drops below $1 \times 10^{6} \mathrm{~km}^{2}$ for at least 5 consecutive years. To determine global temperature at which ice-free conditions occur as presented in Fig. 6, we use a 5-year running mean of global mean annual surface temperature. Global mean annual surface temperature is calculated from area-weighted monthly means of surface temperature and then annually averaged.

\section{Evolution of sea ice extent and volume in extended RCPs}

The multi-model mean time series of Arctic sea ice extent and volume are shown in Fig. 2 for March and September for RCP2.6, RCP4.5, and RCP8.5 through 2300. We show the unsmoothed time series of observations for sea ice extent from Meier et al. (2012) and reanalysis of sea ice volume from Schweiger et al. (2011) in black. The observations fall well within the model spread. The trends in observed extent and reanalysis volume are generally more negative than the trends in multi-model means, though the spread in trends of individual ensemble members encompasses the observations (Stroeve et al., 2012; Massonnet et al., 2012). The spread in modeled sea ice volume is quite large in September at the end of the 20th century. This partially reflects the poorly observed constraint on sea ice volume since time-series estimates of sea ice thickness or volume have been difficult to assess until 

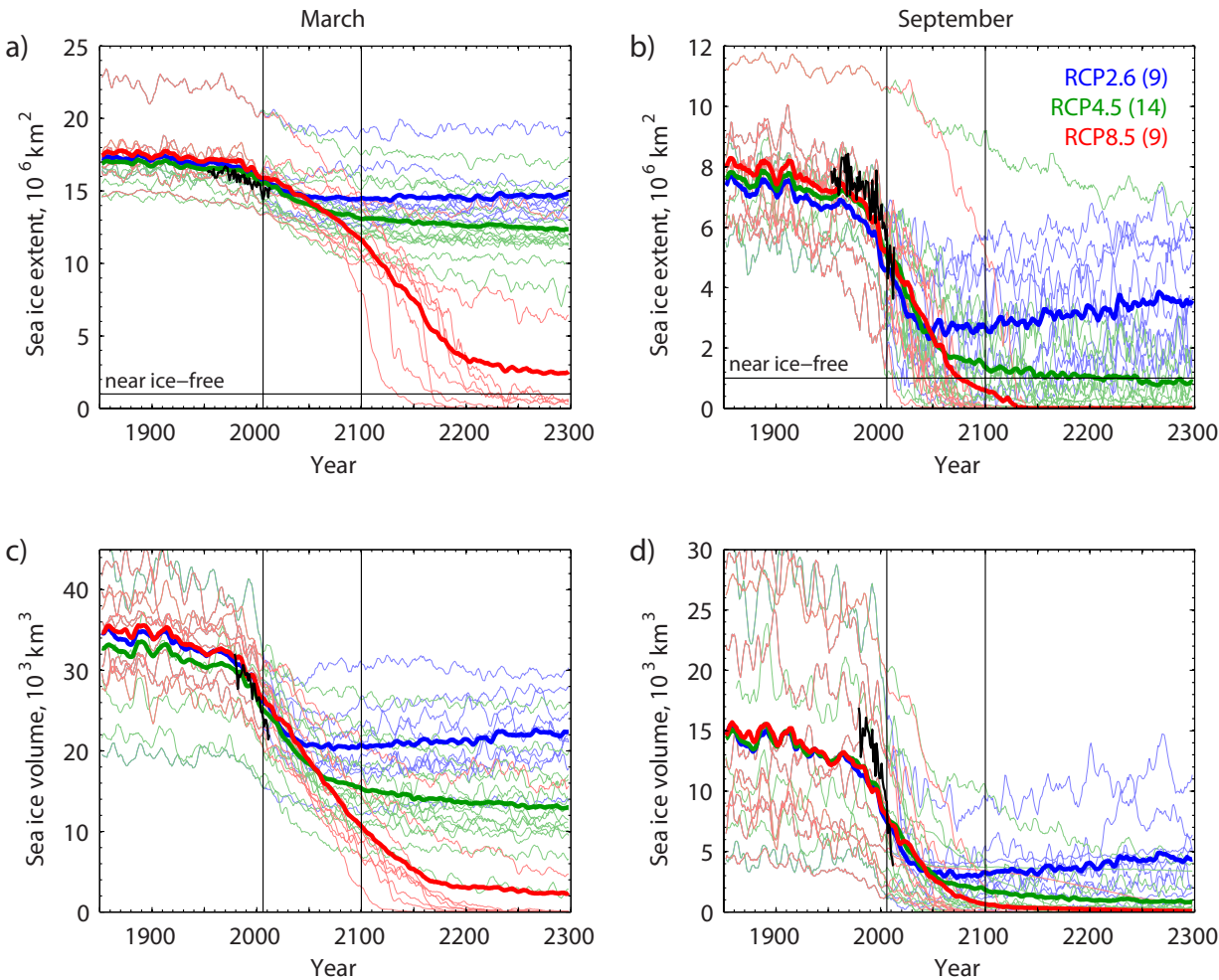

Figure 2. The multi-model mean time series of Arctic sea ice extent, $10^{6} \mathrm{~km}^{2}$, (top) and sea ice volume, $10^{3} \mathrm{~km}^{3}$, (bottom) for March (left) and September (right) under RCP2.6 (blue), RCP4.5 (green), and RCP8.5 (red) from 1850 to 2300. Individual ensemble members are shown as lighter lines (5-year running mean). One ensemble member is used from each model. The time series in the historical period (through 2005) differ slightly because of the different models available for each scenario. The number of models used is given in parentheses next to the RCP. For comparison, observed sea ice extent (black) is from Meier et al. (2012). This data set combines observations from passive microwave sensors and the HadISST time series. Reanalysis of sea ice volume (black) is from the PIOMAS model (Schweiger et al., 2011), and is the "unadjusted" time series.

very recently (Schweiger et al., 2011; Kwok et al., 2009). We discuss in the following subsections the Arctic sea ice evolution from each of the extended RCPs separately. The individual time series for each model are shown in Figs. 3 and 4.

\subsection{Extended RCP2.6}

The forcing for extended RCP2.6 peaks at nearly $3 \mathrm{~W} \mathrm{~m}^{-2}$ around 2044, and begins a monotonic slow decline to $2.6 \mathrm{~W} \mathrm{~m}^{-2}$ by 2100 and to $1.65 \mathrm{~W} \mathrm{~m}^{-2}$ by 2300 (see Fig. 1a). Soon after the forcing begins to decrease, the global mean annual surface temperature also begins to decrease. It does remain higher, however, by a multi-model mean of $0.73^{\circ} \mathrm{C}$ (range $0.35-1.4^{\circ} \mathrm{C}$ ) at the end of the simulation $(2281-2300$ ) compared to the period 1986-2005, which is the period of approximately equivalent forcing.

The sea ice responds relatively quickly to the change in forcing. This is shown by the the reversal of the multi-model mean sea ice extent decline at about the same time as the peak in forcing in 2044. For individual models there is a time lag of up to 6 decades between 2044 and the minimum SIE due to large natural variability at reduced SIE and the relatively weak decline in forcing. In spite of the variability, an increasing sea ice trend is evident in nearly all the extended time series through 2300. September Arctic sea ice extent trends between 2044 and 2300 are positive in eight of nine models (at the $95 \%$ confidence interval, following Santer et al., 2008), and the summer Arctic sea ice extent is larger at the end of the 23rd century than the minimum extent between 2006 and 2300 in all nine models. By the end of the 23rd century, the models have recovered a mean of $44 \%$ of the sea ice extent lost between 1986 and 2005 and the minimum sea ice extent in each ensemble member. Sea ice volume recovers a multi-model mean of $37 \%$ of the amount lost over the same time period, indicating that the mean ice thickness is lower as it recovers. Winter (March) sea ice extent also begins to recover in some of the models as the forcing decreases, but at a slower rate. All but two models (CESM1CAM5.1 and GISS-E2-R) show roughly the same sensitivity (well within a factor of two) in September Arctic sea ice extent and volume per degree global temperature change when global temperature is on a decreasing trajectory compared to when global temperature is on an increasing trajectory. 
CMIP5 Arctic sea ice extent in extended RCPs, March and September
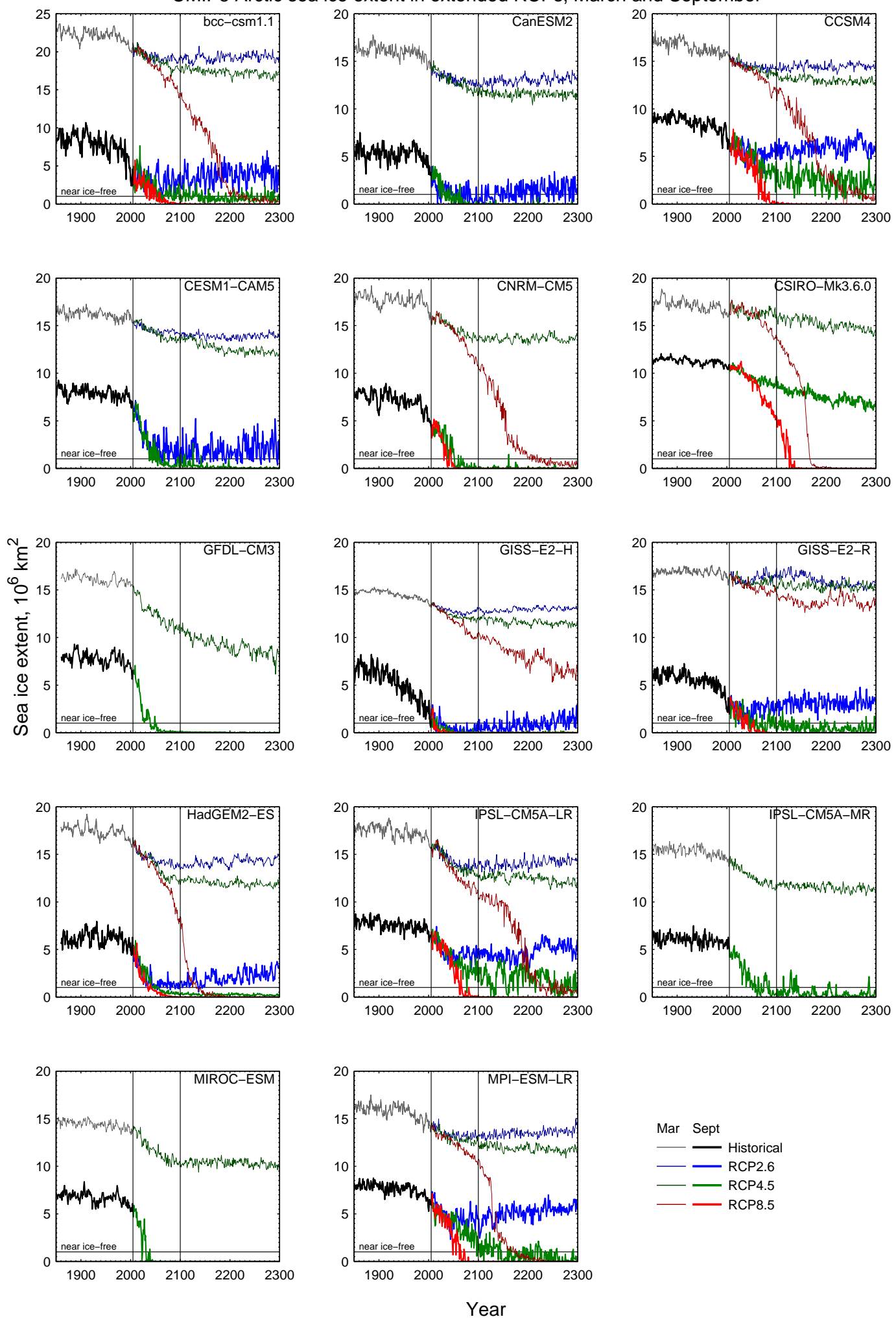

Figure 3. For each model, the time series of Arctic sea ice extent, $10^{6} \mathrm{~km}^{2}$, for September and March for each of the historical and RCP scenarios. The time series is calculated as the area of sea ice concentration $>15 \%$ on the original model grids. No smoothing is applied. Vertical lines indicate 2005 (the end of the historical period) and 2100. A horizontal line at $1 \times 10^{6} \mathrm{~km}^{2}$ shows the threshold for the Arctic being ice-free. 
CMIP5 Arctic sea ice volume in extended RCPs, March and September
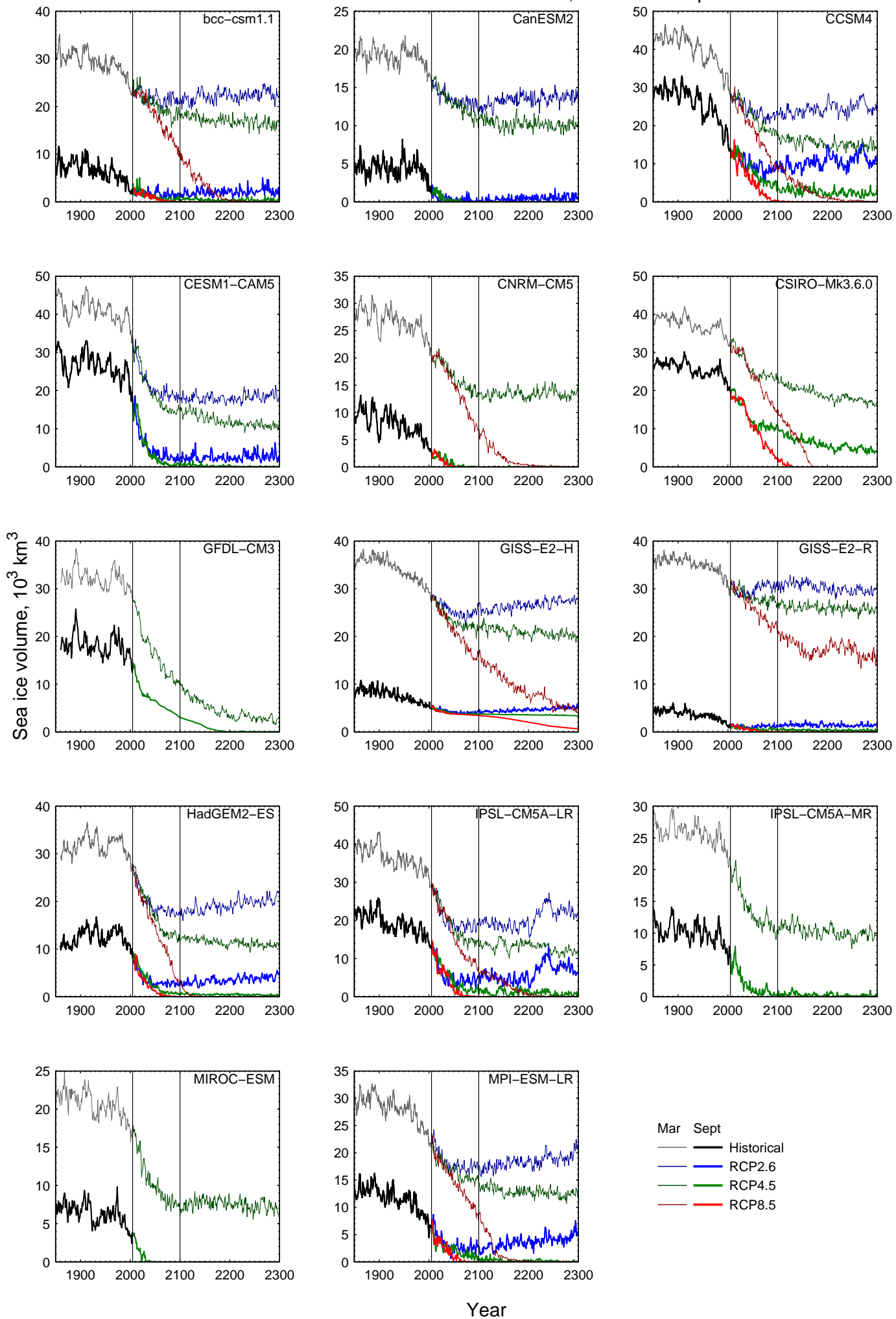

Figure 4. As in Fig. 3, for Arctic sea ice volume, $10^{3} \mathrm{~km}^{3}$. 
We find no convincing relationships between the sea ice climatological state (sea ice extent, volume, seasonal cycle, etc.) and the rate of increase in sea ice extent or volume. Among the models, there is no consistent change toward higher or lower sensitivity of sea ice to temperature under decreasing temperatures compared to increasing temperatures. Even though there is a hysteresis in temperature with respect to the forcing due to the residual effect of the slower components of climate warming, there is no evidence of hysteresis in sea ice extent or volume with respect to increasing and decreasing temperatures.

\subsection{Extended RCP4.5}

In RCP4.5, the forcing becomes nearly constant by 2069 and continues to remain constant through 2300 (see Fig. 1a). Both the Arctic sea ice extent and volume continue to decline after 2069 in all months in 13 of 14 models (Fig. 2). Nine of 14 models have already reached ice-free conditions in September in RCP4.5 by 2069, and so the rates of decline in September sea ice extent are small for these models after the forcing stabilizes (see Massonnet et al., 2012). Three additional models are ice-free in September by 2145 . Of the 12 models that reach summer ice-free conditions, 5 exhibit low frequency oscillations or high interannual variability in September sea ice extent through the period 2100-2300 (see Fig. 3). As can be seen in Fig. 3 in both RCP2.6 and RCP4.5, the interannual variability in Arctic sea ice extent has a tendency to increase as the Arctic approaches seasonally icefree conditions (Goosse et al., 2009). The lower mean thickness of sea ice means that the ice area subject to either complete seasonal melting or survival through the melt season increases. The sea ice extent therefore is more susceptible to interannual variations in both solar radiative (e.g., cloud cover) and advective temperature forcing variations as well as variations in wind-driven convergence.

\subsection{Extended RCP8.5}

The sea ice response to the forcing in extended RCP8.5 is sharper than in RCP4.5. September sea ice disappears in eight models between 2012 and 2077 (followed by the ninth in 2128), with a mean date of disappearance of 2059. In all but two of the models (GISS-E2-R and GISS-E2-H), the March sea ice disappears as well between 2134 and 2234, with a mean date of 2197. The date of disappearance of sea ice for each model in RCP8.5 is shown in Fig. 5 for each month of the year. The mean length of time between the summer and winter disappearance is 129 years (range 41174 years). We discuss insights into the global mean annual temperature at which Arctic sea ice disappears in the section below.

For some models, most notably MPI-ESM-LR, the time series of March sea ice extent in RCP8.5 is non-linear in the decline toward an annual ice-free state (Fig. 3), which is

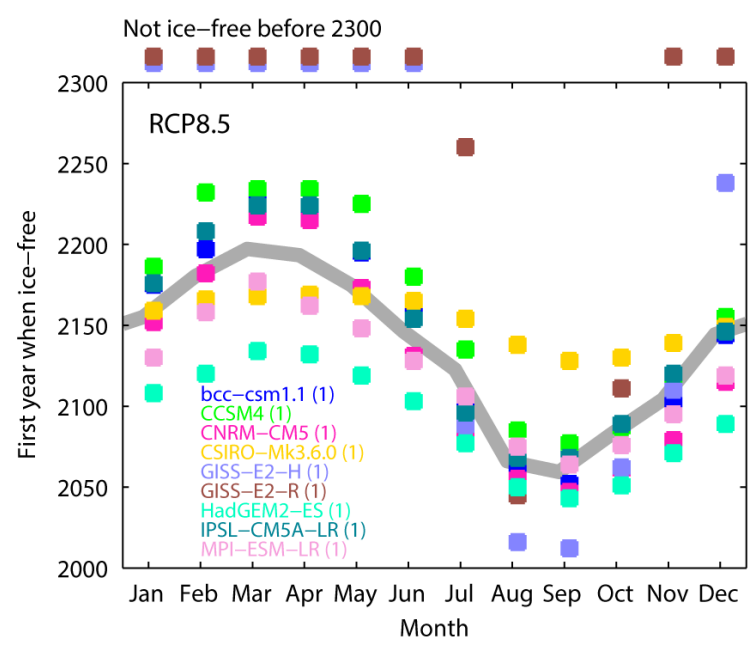

Figure 5. First date of sea ice-free conditions in the Arctic Ocean by month for RCP8.5. The months for which sea ice does not disappear during the simulation are given as symbols above the graph. The multi-model mean is shown by the thick gray line. Disappearance is the first year of at least 5 consecutive years where sea ice extent is $<1 \times 10^{6} \mathrm{~km}^{2}$, based on a 5-year running mean of sea ice extent.

suggestive of a threshold behavior. Eisenman (2012) showed the theoretical possibility that the winter sea ice reaches an unstable equilibrium point after which it decreases rapidly. In all but two models, however, sea ice volume demonstrates a continuing linear or slower rather than faster rate of decline through the disappearance of winter ice, and thus we conclude that apparent threshold behavior is not occurring in this set of models as the winter sea ice disappears.

The occurrence of annually ice-free states has been studied with a hierarchy of models of increasing complexity (e.g., Eisenman, 2012; Winton, 2006, 2008; Ridley et al., 2012; Armour et al., 2011), though a clear driving mechanism for the winter ice-free state has not yet been identified. The loss of winter sea ice has also been documented elsewhere for two of the CMIP5 models (MPI-ESM-LR and CCSM4) (Li et al., 2013; Meehl et al., 2012, 2013; Jahn and Holland, 2013), with several mechanisms invoked as contributors to lack of winter ice growth. In investigations with a single global climate model, Abbot et al. (2009) suggest that a winter convective-cloud feedback coupled with an ocean heat transport feedback is necessary to prevent winter radiative energy loss to space and thus prevent sea ice formation. Though a full investigation of the mechanism leading to a lack of ice growth is beyond the scope of this paper, preliminary analysis of the surface energy fluxes suggests that enhanced downward longwave flux during the summer months may also play a role. 


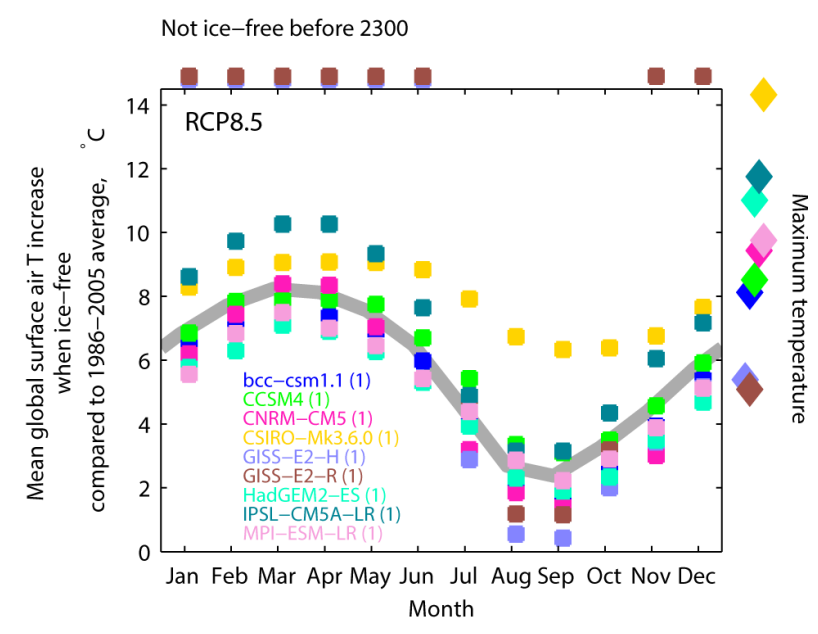

Figure 6. Global mean annual surface air temperature increase compared to 1986-2005 average, at which the Arctic Ocean becomes sea ice-free for RCP8.5. The multi-model mean is shown by the thick gray line. Months for which sea ice does not disappear are given as symbols above the graph. The maximum global surface temperature increase for each simulation is shown to the right of each graph.

\section{Global temperature increase at which sea ice disappears}

Figure 6 shows the global annual mean surface temperature increase (compared to 1986-2005 average) at which the Arctic sea ice disappears for RCP8.5. September sea ice disappears with a mean temperature increase of $2.4^{\circ} \mathrm{C}$ (range 0.4 $6.2^{\circ} \mathrm{C}$ ), and March sea ice disappears at a mean temperature increase of $8.2^{\circ} \mathrm{C}$ (range $7.1-10.3^{\circ} \mathrm{C}$ ). In general, with the exception of the CSIRO-Mk3.6.0, GISS-E2-R and GISSE2-H models, the models are in broad agreement regarding the additional global temperature increase under which sea ice disappears beyond September, including winter sea ice disappearance (i.e., temperature difference between winter and summer sea ice disappearance). The summer sea ice in the GISS-E2-R and GISS-E2-H models is very sensitive to changes in global temperature, which leads to an early date of disappearance, yet the rates of winter sea ice decline throughout the simulations are roughly constant. CSIRO-Mk3.6.0 is the least sensitive with respect to the loss of summer sea ice, but the winter sea ice is the most sensitive to additional global temperature increase.

The global annual mean surface temperature warming at which September Arctic sea ice disappears is consistent with the range determined by Mahlstein and Knutti (2012) for the CMIP3 models. The temperature at which sea ice disappears in RCP4.5 is also consistent with RCP8.5. In the seven models that lose September sea ice in both the RCP4.5 and RCP8.5 simulations, the mean temperature at which September sea ice disappears is lower in RCP 4.5 by $0.18 \pm 0.38^{\circ} \mathrm{C}$. Global mean temperatures do not increase enough in any of the models under RCP4.5 to reach the threshold at which the winter sea ice disappears, as the maximum increase in temperature beyond the $1986-2005$ average is less than $4{ }^{\circ} \mathrm{C}$ for all models. Agreement between RCP4.5 and RCP8.5 with respect to temperature at which sea ice disappears underscores the idea that the sea ice responds to the changes in global forcing reflected in the global mean surface temperature, regardless of the forcing trajectory which results in that temperature increase (Jahn and Holland, 2013).

\section{Reversibility of sea ice extent decline in global models}

RCP2.6 is the first CMIP scenario which follows a future trajectory of increasing radiative forcing, followed by decreasing radiative forcing applied to multiple models. It demonstrates that decreases in summer Arctic sea ice extent are reversible over the range of global surface temperature increases and seasonal ice loss simulated under this scenario. Although RCP2.6 represents the lowest forcing scenario, the rate of increase of radiative forcing is similar in both RCP2.6 and RCP4.5 through 2044. We also note here that a multimodel mean of $80 \%$ of the decline in September sea ice extent between 1995 and 2069 in RCP4.5 has occurred by 2044, the time of the peak forcing in RCP2.6. It might be expected therefore that a similar reduction in forcing under the higher forcing scenario of RCP4.5 would result in a similar summer Arctic sea ice recovery.

A comparison of sea ice extents under a scenario of decreasing radiative forcing was also carried out with a subset of CMIP3 models within the ENSEMBLES project (Johns et al., 2011; Körper et al., 2013) with a radiative forcing trajectory that is similar to that of RCP2.6 (see Fig. 2 in Johns et al., 2011). In those results, September Arctic sea ice extent did not increase after the forcing began to decrease (see Fig. 9 in Körper et al., 2013), but the simulations were short and ended in 2100. In the RCP2.6 simulations here, ice extent trends between 2044 and 2100 are not significantly different from zero. Though we cannot rule out that the CMIP3 models respond differently from the CMIP5 models, it is likely that the short length of the ENSEMBLES project mitigation scenarios combined with natural variability in the models hid the beginning of a long-term recovery of summer Arctic sea ice in that study. The recovery is evident only when considered on timescales beyond those of natural variability and therefore only in the extended RCP2.6 simulations shown in this paper.

Much attention has been focused on the fact that Arctic sea ice has been declining more rapidly than most models over the satellite era (e.g., Stroeve et al., 2012). The forced part of recent SIE trend may be reinforced by natural variability (Kay et al., 2011), and the lack of agreement between models and observations may be overstated since the models would not be expected to capture the exact timing of this rapid decline. If, however, the recent rapid decline in Arctic sea ice 
indicates that the models are less sensitive to the forcing than the true climate system (Winton, 2011), there is a possibility that model-derived estimates of the mean global surface warming which result in an ice-free state may be overestimated. If feedbacks within the natural system drive a faster sea ice loss rate than the loss rate estimated by models and these occur on short timescales (up to several years), then it is possible that the sea ice response to a reduction in forcing could be similarly more rapid than modeled in CMIP5.

\section{Conclusions}

We have shown here the evolution of Arctic sea ice extent and volume in the extended RCP2.6, RCP4.5, and RCP8.5. RCP2.6 demonstrates an increase in September ice extent in all nine models as the radiative forcing in that scenario decreases after 2044 through 2300. In RCP4.5, 9 of 14 models have already become seasonally ice-free in September before the peak in radiative forcing, and an additional 3 models are ice-free in September by 2145. In RCP8.5, the September Arctic sea ice disappears in all nine models, and the winter sea ice also disappears in seven of nine models under this scenario. Though the timing of the disappearance of September sea ice is not well constrained by the CMIP5 models, the global mean annual temperature increase at which sea ice disappears is fairly robust, both across models and across RCP scenarios.

From a policy perspective, extended RCP2.6 indicates that a recovery of Arctic sea ice could begin if and when policies to reduce global greenhouse gas concentrations and hence radiative forcing are implemented. Extended RCP4.5 further shows that a plateau in the forcing may not be sufficient to prevent continued Arctic sea ice loss and a seasonally icefree state even if the decrease in forcing begins before the disappearance of summer sea ice. In practice, a reduction in forcing to prevent further sea ice loss needs to be sufficiently large to dominate the recalcitrant warming expected from heat storage in slowly evolving parts of the climate system (e.g., deep ocean) (Held et al., 2010). The threshold at which a forcing reduction maintains a constant global mean temperature would itself be a function of the estimated equilibrium and transient climate sensitivities of the Earth system. As the RCP scenarios do not incorporate interactive carbon cycle processes and feedbacks, the impact of such processes would need to be considered in the design of any strategies to reduce radiative forcing.

Acknowledgements. We acknowledge the World Climate Research Programme's Working Group on Coupled Modelling, which is responsible for CMIP, and we thank the climate modeling groups for producing and making available their model output. The US Department of Energy's Program for Climate Model Diagnosis and Intercomparison provides coordinating support and led development of CMIP software and infrastructure in partnership with the Global Organization for Earth System Science Portals. The authors thank J. Sedláček and U. Beyerle at ETH Zürich for providing an easy interface for obtaining the CMIP5 data set. FM is a F.R.S-FNRS Research Fellow. This research was supported by the Belgian Federal Science Policy Office (BELSPO) and by the European Commission 7th Framework Programme, under grant agreement no. 226520, COMBINE project (Comprehensive Modelling of the Earth System for Better Climate Prediction and Projection).

Edited by: L. Kaleschke

\section{References}

Abbot, D. S., Huber, M., Bousquet, G., and Walker, C. C.: High$\mathrm{CO}_{2}$ cloud radiative forcing feedback over both land and ocean in a global climate model, Geophys. Res. Lett., 36, L05702, doi:10.1029/2008GL036703, 2009.

Arctic Monitoring and Assessment Programme (AMAP): Snow, Water, Ice and Permafrost in the Arctic (SWIPA): Climate Change and the Cryosphere, Oslo, Norway, 2011.

Armour, K. C., Eisenman, I., Blanchard-Wrigglesworth, E., McCusker, K. E., and Bitz, C. M.: The reversibility of sea ice loss in a state-of-the-art climate model, Geophys. Res. Lett., 38, L16705, doi:10.1029/2011GL048739, 2011.

Collins, M., Knutti, R., Arblaster, J., J.-L. Dufresne, T. F., Friedlingstein, P., X. Gao, W. G., Johns, T., Krinner, G., Shongwe, M. Tebaldi, C., Weaver, A., and Wehner, M.: Long-term climate change: projections, commitments and irreversibility, in: Climate Change 2013: The Physical Science Basis. Contribution of Working Group I to the Fifth Assessment Report of the Intergovernmental Panel on Climate Change, edited by: Stocker, T., Qin, D., Plattner, G.-K., Tignor, M., Allen, S., Boschung, J., Nauels, A., Xia, Y., Bex, V., and Midgley, P., Cambridge University Press, Cambridge, UK and New York, NY, USA, 2013.

Eisenman, I.: Factors controlling the bifurcation structure of sea ice retreat, J. Geophys. Res.-Atmos., 117, D01111, doi:10.1029/2011JD016164, 2012.

Goosse, H., Arzel, O., Bitz, C. M., de Montety, A., and Vancoppenolle, M.: Increased variability of the Arctic summer ice extent in a warmer climate, Geophys. Res. Lett., 36, L23702, doi:10.1029/2009GL040546, 2009.

Hansen, J., Nazarenko, L., Ruedy, R., Sato, M., Willis, J., Del Genio, A., Koch, D., Lacis, A., Lo, K., Menon, S., Novakov, T., Perlwitz, J., Russell, G., Schmidt, G. A., and Tausnev, N.: Earth's energy imbalance: confirmation and implications, Science, 308, 1431-1435, doi:10.1126/science.1110252, 2005.

Held, I. M., Winton, M., Takahashi, K., Delworth, T., Zeng, F., and Vallis, G. K.: Probing the fast and slow components of global warming by returning abruptly to preindustrial forcing, J. Climate, 23, 2418-2427, doi:10.1175/2009JCLI3466.1, 2010.

Jahn, A. and Holland, M. M.: Implications of Arctic sea ice changes for North Atlantic deep convection and the meridional overturning circulation in CCSM4-CMIP5 simulations, Geophys. Res. Lett., 40, 1206-1211, doi:10.1002/grl.50183, 2013.

Johns, T., Royer, J.-F., Höschel, I., Huebener, H., Roeckner, E., Manzini, E., May, W., Dufresne, J.-L., Otterå, O., Vuuren, D. Salas y Melia, D., Giorgetta, M., Denvil, S., Yang, S., Fogli, P., Körper, J., Tjiputra, J., Stehfest, E., and Hewitt, C.: 
Climate change under aggressive mitigation: the ENSEMBLES multi-model experiment, Clim. Dynam., 37, 1975-2003, doi:10.1007/s00382-011-1005-5, 2011.

Kay, J. E., Holland, M. M., and Jahn, A.: Inter-annual to multidecadal Arctic sea ice extent trends in a warming world, Geophys. Res. Lett., 38, L15708, doi:10.1029/2011GL048008, 2011.

Körper, J., Höschel, I., Lowe, J., Hewitt, C., Salas y Melia, D., Roeckner, E., Huebener, H., Royer, J.-F., Dufresne, J.-L., Pardaens, A., Giorgetta, M., Sanderson, M., Otterå, O., Tjiputra, J., and Denvil, S.: The effects of aggressive mitigation on steric sea level rise and sea ice changes, Clim. Dynam., 40, 531-550, doi:10.1007/s00382-012-1612-9, 2013.

Kwok, R., Cunningham, G. F., Wensnahan, M., Rigor, I., Zwally, H. J., and Yi, D.: Thinning and volume loss of the Arctic Ocean sea ice cover: 2003-2008, J. Geophys. Res.-Oceans, 114, C07005, doi:10.1029/2009JC005312, 2009.

Lenton, T. M., Held, H., Kriegler, E., Hall, J. W., Lucht, W., Rahmstorf, S., and Schellnhuber, H. J.: Tipping elements in the Earth's climate system, P. Natl. Acad. Sci. USA, 105, 17861793, doi:10.1073/pnas.0705414105, 2008.

Li, C., Notz, D., Tietsche, S., and Marotzke, J.: The transient vs. the equilibrium response of sea ice to global warming, J. Climate, 26, 5624-5636, doi:10.1175/JCLI-D-12-00492.1, 2013.

Lindsay, R. W. and Zhang, J.: The thinning of Arctic Sea Ice, 19882003: have we passed a tipping point?, J. Climate, 18, 48794894, doi:10.1175/JCLI3587.1, 2005.

Liu, J., Song, M., Horton, R. M., and Hu, Y.: Reducing spread in climate model projections of a September icefree Arctic, P. Natl. Acad. Sci. USA, 110, 12571-12576, doi:10.1073/pnas.1219716110, 2013.

Livina, V. N. and Lenton, T. M.: A recent tipping point in the Arctic sea-ice cover: abrupt and persistent increase in the seasonal cycle since 2007, The Cryosphere, 7, 275-286, doi:10.5194/tc-7-2752013, 2013.

Long, D. and Collins, M.: Quantifying global climate feedbacks, responses and forcing under abrupt and gradual $\mathrm{CO}_{2}$ forcing, $\mathrm{Clim}$. Dynam., 41, 2471-2479, doi:10.1007/s00382-013-1677-0, 2013.

Mahlstein, I. and Knutti, R.: September Arctic sea ice predicted to disappear near $2^{\circ} \mathrm{C}$ global warming above present, J. Geophys. Res.-Atmos., 117, D06104, doi:10.1029/2011JD016709, 2012.

Massonnet, F., Fichefet, T., Goosse, H., Bitz, C. M., PhilipponBerthier, G., Holland, M. M., and Barriat, P.-Y.: Constraining projections of summer Arctic sea ice, The Cryosphere, 6, 13831394, doi:10.5194/tc-6-1383-2012, 2012.

Meehl, G. A., Washington, W. M., Arblaster, J. M., Hu, A., Teng, H., Tebaldi, C., Sanderson, B. N., Lamarque, J.-F., Conley, A., Strand, W. G., and White, J. B.: Climate system response to external forcings and climate change projections in CCSM4, J. Climate, 25, 3661-3683, doi:10.1175/JCLI-D-11-00240.1, 2012.

Meehl, G. A., Washington, W. M., Arblaster, J. M., Hu, A., Teng, H., Kay, J. E., Gettelman, A., Lawrence, D. M., Sanderson, B. M., and Strand, W. G.: Climate change projections in CESM1(CAM5) compared to CCSM4, J. Climate, 26, 62876308, doi:10.1175/JCLI-D-12-00572.1, 2013.

Meier, W. N., Stroeve, J., Barrett, A., and Fetterer, F.: A simple approach to providing a more consistent Arctic sea ice extent time series from the 1950s to present, The Cryosphere, 6, 13591368, doi:10.5194/tc-6-1359-2012, 2012.
Meinshausen, M., Smith, S., Calvin, K., Daniel, J., Kainuma, M., Lamarque, J.-F., Matsumoto, K., Montzka, S., Raper, S., Riahi, K., Thomson, A., Velders, G., and Vuuren, D.: The RCP greenhouse gas concentrations and their extensions from 1765 to 2300, Climatic Change, 109, 213-241, doi:10.1007/s10584011-0156-z, 2011.

Moss, R. H., Edmonds, J. A., Hibbard, K. A., Manning, M. R., Rose, S. K., van Vuuren, D. P., Carter, T. R., Emori, S., Kainuma, M., Kram, T., Meehl, G. A., Mitchell, J. F. B., Nakicenovic, N., Riahi, K., Smith, S. J., Stouffer, R. J., Thomson, A. M., Weyant, J. P., and Wilbanks, T. J.: The next generation of scenarios for climate change research and assessment, Nature, 463, 747-756, doi:10.1038/nature08823, 2010.

Notz, D.: Sea-ice extent and its trend provide limited metrics of model performance, The Cryosphere, 8, 229-243, doi:10.5194/tc-8-229-2014, 2014.

Ridley, J. K., Lowe, J. A., and Hewitt, H. T.: How reversible is sea ice loss?, The Cryosphere, 6, 193-198, doi:10.5194/tc-6-1932012, 2012.

Santer, B. D., Thorne, P. W., Haimberger, L., Taylor, K. E., Wigley, T. M. L., Lanzante, J. R., Solomon, S., Free, M., Gleckler, P. J., Jones, P. D., Karl, T. R., Klein, S. A., Mears, C., Nychka, D., Schmidt, G. A., Sherwood, S. C., and Wentz, F. J.: Consistency of modelled and observed temperature trends in the tropical troposphere, Int. J. Climatol., 28, 1703-1722, doi:10.1002/joc.1756, 2008.

Schweiger, A., Lindsay, R., Zhang, J., Steele, M., Stern, H., and Kwok, R.: Uncertainty in modeled Arctic sea ice volume, J. Geophys. Res.-Oceans, 116, C00D06, doi:10.1029/2011JC007084, 2011.

Stroeve, J. C., Kattsov, V., Barrett, A., Serreze, M., Pavlova, T., Holland, M., and Meier, W. N.: Trends in Arctic sea ice extent from CMIP5, CMIP3 and observations, Geophys. Res. Lett., 39, L16502, doi:10.1029/2012GL052676, 2012.

Taylor, K. E., Stouffer, R. J., and Meehl, G. A.: An overview of CMIP5 and the experiment design, B. Am. Meteorol. Soc., 93, 485-498, doi:10.1175/BAMS-D-11-00094.1, 2012.

Tietsche, S., Notz, D., Jungclaus, J. H., and Marotzke, J.: Recovery mechanisms of Arctic summer sea ice, Geophys. Res. Lett., 38, L02707, doi:10.1029/2010GL045698, 2011.

Wadhams, P.: Arctic ice cover, ice thickness and tipping points, AMBIO, 41, 23-33, doi:10.1007/s13280-011-0222-9, 2012.

Wang, M. and Overland, J. E.: A sea ice free summer Arctic within 30 years: an update from CMIP5 models, Geophys. Res. Lett., 39, L18501, doi:10.1029/2012GL052868, 2012.

Winton, M.: Does the Arctic sea ice have a tipping point?, Geophys. Res. Lett., 33, L23504, doi:10.1029/2006GL028017, 2006.

Winton, M.: Sea ice - Albedo feedback and nonlinear Arctic climate change, in: Arctic Sea Ice Decline: Observations, Projections, Mechanisms, and Implications, edited by: DeWeaver, E. T., Bitz, C. M., and Tremblay, L.-B., American Geophysical Union, Washington, D.C., 180, 111-131, doi:10.1029/180GM09, 2008.

Winton, M.: Do climate models underestimate the sensitivity of Northern Hemisphere sea ice cover?, J. Climate, 24, 39243934,doi:10.1175/2011JCLI4146.1, 2011.

Zhang, X.: Sensitivity of arctic summer sea ice coverage to global warming forcing: towards reducing uncertainty in Arctic climate change projections, Tellus A, 62, 220-227, doi:10.3402/tellusa.v62i3.15690, 2010. 